\title{
THE STUDY OF THE EFFECTS OF RADIATION AND BLOWING FROM THE WALL OF A VERTICAL CHANNEL ON THE TURBULENT FREE CONVECTION HEAT TRANSFER
}

\author{
Ali Yari ${ }^{1}$, Siamak Hosseinzadeh ${ }^{2 *}$, Amin Bahrami $^{3}$, Morteza Radmanesh ${ }^{4}$ \\ ${ }^{1}$ Department of Mechanical Engineering, University of Shiraz, Shiraz, Iran \\ Ali.Yari.Engineeregmaail.com \\ $2^{*}$ Department of Mechanical Engineering, Islamic Azad University, West Tehran \\ Branch, Tehran, Iran \\ Hoseinzadeh.siamak@gmail.com \\ ${ }^{3}$ Department of Mechanical Engineering, University of Science and Technology, \\ Tehran, Iran \\ aminbahrami87@yahoo.com \\ ${ }^{4}$ Department of Mechanical Engineering, University College of Rouzbahan, Sari, Iran \\ morteza.radmanesh20@yahoo.com
}

\begin{abstract}
This article investigates the effects of radiation and blowing from a wall on a turbulent heat transfer in vertical channels with asymmetrical heating. The equations involved were numerically solved with three turbulent models including Spalart Allmaras, $R-N-G k-\varepsilon$ with "Standard Wall Function" wall nearby model, $R-N-G$ k- $\varepsilon$ with "Enhanced Wall Treatment" wall nearby model and "Ray Tracing" radiation techniques. The results were compares with experimental data and appropriate methods were selected for turbulent modeling. The problem of Rayleigh number, Reynolds, radiation parameters and Prandtl were solved and the effects of these parameters on the flow lines, lines of constant temperature, radiation, convection, heat transfer caused by blowing and the total heat transfer were determined.
\end{abstract}

\section{Keywords}

Turbulent free convection, Radiation, Blowing, Channel flow.

\section{INTRODUCTION}

Heat transfer convection from vertical plates with constant temperature or constant heat flux has highly been considered by researchers. Most researches in this field of did analytical studies of flow in calm area and less attention has been paid to the turbulent flow. In turbulent flows, Miyamoto et al [1], did a laboratory study on the free convection of turbulent flow inside vertical channels. The boundary condition of their experimental channel was constant temperature or pressure. They reported the velocity, temperature and heat transfer rate across the channel. Fedorov and Viskanta [2], used low Reynolds k- $\varepsilon$ model to study the free convection flow from a channel which has one adiabatic channel and another wall with constant heat flux in order to find a suitable model for modelling and estimating heat transfer rate and temperature. Their results show a good match with Miamoto's [1] laboratory study. On the other hand, the way blowing fluid blowing can affect heat transfer rate is one the issues which has long investigated. In the boundary layer, blowing can cause the boundary layer to increase and make the flow turbulent. The effect of blowing and suction on the free convection was proposed by HORN [3], which was solved using a similarity method for a vertical wall with temperature profile of space function. The results showed that blowing and suction in the calm flow has a significant influence on heat transfer rate. There are similar articles in the field that investigated 
the effects of blowing and suction on the heat transfer rate with other methods (or in more general states) [4-6]. The effect of radiation on the mixed heat transfer in a vertical channel with calm and completely developed flow was numerically and analytically studies by Grosan [7]. Rosseland method was applied for radiation in which the wall temperature was considered to be constant. Velocity and temperature profiles were drawn based on changes in radiation parameters, and it was indicated that when the radiation parameters increase, the return flows decrease.

In many modern systems like compact heat exchangers and electronic components, the focus is on the mutual effects of free turbulent model on radiation. Chang and Muller [8], in a numerical and laboratory study, investigated the turbulent free convection flow of air along with heat radiation in a three dimensional rectangular channel with a constant- temperature heated wall. The study was done for high Reynolds numbers. They analysed the effects of changes in the temperature and the coefficient of issued heated wall on the velocity and temperature profiles, air mass flow suctioned from the end of the channel and heat transfer. On the other hand, some issues such as heat transfer convection, radiation and blowing have recently been greatly considered. Abdolaziz ' studies show the effects of heat penetration heat transfer properties and free convection transfer from a penetrable plate with blowing-suction, radiation and magnetic field, in which parameter like temperature and Nusslet number were studied. The issues which have been investigated in this study are the quality of heat transfer in vertical channels with three parameters including free turbulent convection, radiation and blowing which have never been studied before.

\section{PHYSICAL MODEL}

The study consists of a channel with two parallel plates, the height $\mathrm{H}$ and width $\mathrm{L}$. The left wall is isolated and the right wall is latticed with constant temperature. Hot gas blow with equal temperature as the wall and with a uniform and constant velocity from a latticed wall with holes of $d$ diameters and distance of from each other. A floating force causes the flow in channel. In the entrance of the channel, the fluid enters with environment temperature and atmosphere pressure and the output heated gas is discharged to the atmosphere.

\section{THE GOVERNING EQUATIONS OF FLUID FLOW}

Fluid properties are assumed constant, except density in terms of free convection in the momentum equations, which are modelled assuming the Boussinesq. All levels are assumed to be grey with the radiation properties independent of wave length and radiation coefficient with equal absorption coefficient and non-participant fluid in the radiation process. The governing equations for steady two-dimensional non- compressible state, using conservation laws of mass, momentum and energy, can be written as flows:

$\left(\rho V_{i}\right)_{, i}=0$

$\rho V_{j} \frac{\partial V_{i}}{\partial X_{j}}=\mu \frac{\partial}{\partial X_{j}}\left(\frac{\partial V_{i}}{\partial X_{j}}\right)+g_{i} \beta\left(T-T_{\infty}\right)$

$\rho C_{p} V_{j} \frac{\partial T}{\partial X_{j}}=-\beta T V_{j} \frac{\partial P}{\partial X_{j}}+\mu\left(\frac{\partial V_{i}}{\partial X_{j}}+\frac{\partial V_{j}}{\partial X_{i}}\right) \frac{\partial V_{i}}{\partial X_{j}}+k_{t h} \frac{\partial}{\partial X_{i}}\left(\frac{\partial T}{\partial X_{i}}\right)$

In which all the parameters have their own common definitions. The right wall has the constant temperature, $\mathrm{T}_{1}$ and the left wall is isolated, because radiation flux and convection flux are equal in this boundary $\left(\mathrm{q}_{\mathrm{c}}=\mathrm{q}_{\mathrm{r}}\right)$. Using "radiation tracing" technique, a system of radiation equations 
are obtained, solving which, as well as solving the conservation equations above, may result temperature and flow field.

\section{THE MATHEMATICS OF DEVELOPMENT}

\subsection{Validity of the results}

Numerical results of free convection heat transfer in a vertical channel with asymmetric wall heat without blowing were compared with the experimental data of Cheng and Muller [2]. In this solution, the channel height is 8 meters and the width of the channel is 0.5 meters, the wall temperature is 150 centigrade, the input air temperature is 20 degree centigrade, radiation coefficient 0.9 , Prandtl number 0.72 and the Rayleigh number equals to $6.5 \times 10^{8}$. To model the turbulent flow, three turbulent models including Spalart Allmaras, RNG k- $\varepsilon$ with "Standard Wall Function" wall nearby model, RNG k- $\varepsilon$ with "Enhanced Wall Treatment" wall nearby model and "Ray Tracing" radiation techniques were used. To grid computational limit, a nonuniform $\mathrm{H}$ grid was as shown in figure (1). To ensure the independence of the results from the grid, a grid study was done for all the three models. Table (1) shows the average difference of the velocity and temperature profiles in the output of the channel with the experimental data in all the three models. Also, in figures (2) and (3) the most precise numerical results in all the three turbulent models in velocity and temperature profiles in the output of the channel were compared with the experimental data, which show that Spalart Allmaras modelling has a good match with the experimental data. Therefore, the final modelling is done based this method. The use of a grid with less than 80,000 computational grid cells is not possible for this method due to $y+$ constraints. For all the results presented this network density or better than this were used.

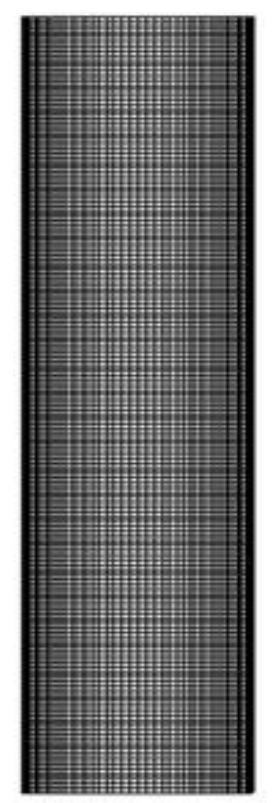

Figure 1. A non-uniform network of computational zone

Table 1. Shows the average difference of the velocity and temperature profiles

\begin{tabular}{|l|l|l|l|}
\hline Turbulent & Mesh & $\begin{array}{l}\text { Average } \\
\text { Velocity } \\
\text { Error }\end{array}$ & $\begin{array}{l}\text { Average } \\
\text { Temperatu } \\
\text { re Error }\end{array}$ \\
\hline
\end{tabular}


International Journal of Recent advances in Mechanical Engineering (IJMECH) Vol.3, No.4, November 2014

\begin{tabular}{|l|l|l|l|}
\hline \multirow{3}{*}{$\begin{array}{l}\text { Spalart } \\
\text { Allmaras }\end{array}$} & 80000 & $\% 12$ & $\% 18$ \\
\cline { 2 - 4 } & 12000 & $\% 12$ & $\% 18$ \\
\cline { 2 - 4 } & $\begin{array}{l}20000 \\
0\end{array}$ & $\% 12$ & $\% 18$ \\
\hline $\begin{array}{l}\text { RNG k- } \varepsilon \\
\text { (Enhanced } \\
\text { Wall } \\
\text { Treatment) }\end{array}$ & 36000 & $\% 19$ & $\% 26$ \\
\cline { 2 - 4 } & 60000 & $\% 19$ & $\% 26$ \\
\hline $\begin{array}{l}\text { RNG k- } \varepsilon \\
\text { (Standard Wall } \\
\text { Function) }\end{array}$ & 4000 & $\% 27$ & $\% 34$ \\
\cline { 2 - 4 } & 8000 & $\% 27$ & $\% 34$ \\
\hline
\end{tabular}

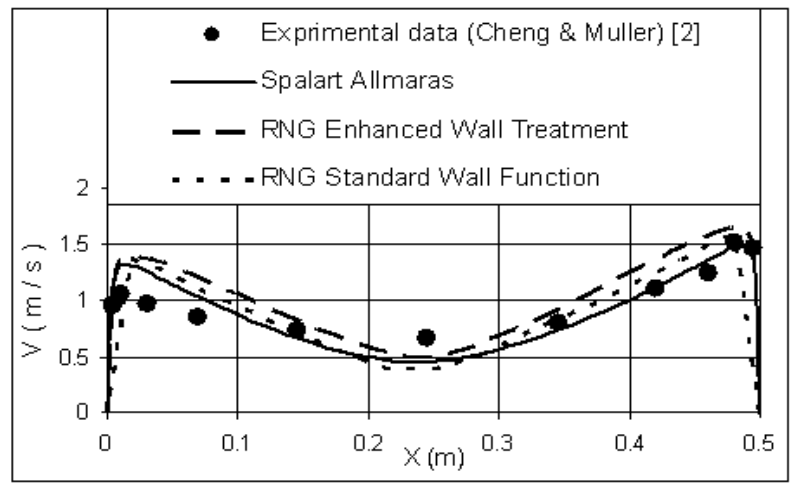

Figure 2. The velocity profile at the channel output

$\left(\mathrm{Ra}=108 \times 6.5 \cdot \operatorname{Pr}=0.72 \cdot \varepsilon=0.9, \mathrm{~T} 1=150^{\circ} \mathrm{c} \cdot \mathrm{T} \infty=20^{\circ} \mathrm{c} \cdot \mathrm{L}=0.5 \mathrm{~m} \cdot \mathrm{H}=8\right)$

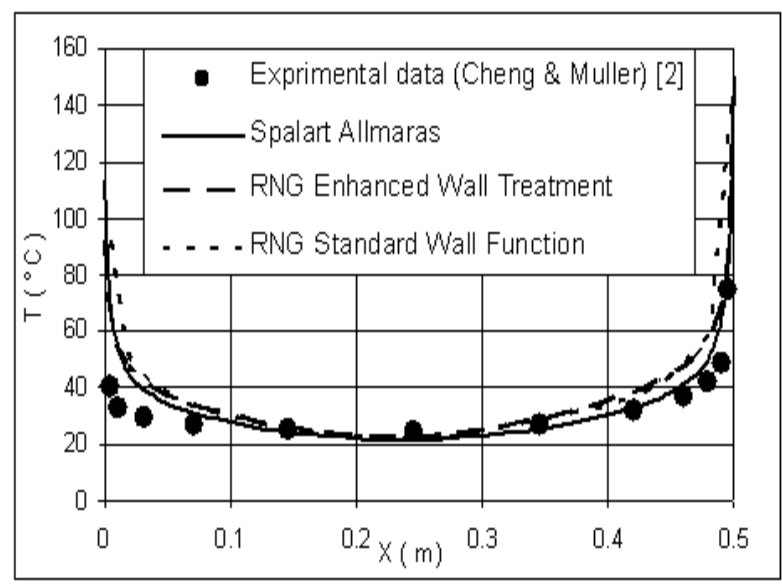

Figure 3. Temperature profiles at the channel output

$$
\left(\mathrm{Ra}=108 \times 6.5 \cdot \operatorname{Pr}=0.72 ، \varepsilon=0.9, \mathrm{~T} 1=150^{\circ} \mathrm{c} \cdot \mathrm{T} \infty=20^{\circ} \mathrm{c} \cdot \mathrm{L}=0.5 \mathrm{~m} \cdot \mathrm{H}=8\right)
$$

\subsection{Results and Discussion}

The flow in the discussed geometry, is considered to be a function of 6 independent dimensionless parameters which include : Rayleigh number relative to the vertical height of the 
screen, $\mathrm{Ra}_{\mathrm{H}}$, radiation parameters (Stefan number), Stef, Prandtl, Pr, the ratio of channel height to the width and the ratio of grooves diameter to the width of the channel $\mathrm{d} / \mathrm{L}$. in this article, the results are presented concerning the effect of four parameters: Rayleigh number for the vertical heated plate, blowing Reynolds number, Radiation parameters (Stefan number) and Prandtl. The four parameter variables are defined respectively as follows:

$$
R a_{H}=\frac{g \beta \Delta T H^{3}}{\alpha v} \quad \text { (4) } \quad \operatorname{Re}_{B}=\frac{\rho V_{B} d}{\mu} \quad \text { (5) } \quad \text { Stef }=\frac{4 \sigma \cdot \varepsilon \cdot T_{1}^{3} \cdot L}{k} \quad \text { (6) } \quad \operatorname{Pr}=\frac{v}{\alpha}
$$

In which is defined as:

$\Delta T=T_{1}-T_{\infty}$

It is important to recognize that how changing of any of these variables will affect the flow parameters. In order to do so, we have solved the problem for different amounts of every dimensionless number. The boundary condition and quantities of fluid properties in all condition were considered, in which as vary parameter changes, the other dimensionless numbers remain constant. For every component of heat transfer (free convection, radiation and blowing), Nusslet number is defined by the following equation:

$$
N u_{c}=\frac{h_{c} H}{k}=\frac{Q_{c}}{k \Delta T} \quad \text { (9) } \quad N u_{r}=\frac{h_{r} H}{k}=\frac{Q_{r}}{k \Delta T} \quad \text { (10) } \quad N u_{b}=\frac{h_{b} H}{k}=\frac{Q_{b}}{k \Delta T}
$$

$Q_{r} \& Q_{b}$ respectively indicate the heat transfer caused by radiation and the heat transfer caused by mass convection (blowing). $N u_{r} \& N u_{b}$ are in fact an equation for Nusslet number in radiation and blowing processes. Although they do not encompass the physical definition of Nusslet convection, they can be applied to compare between heat transfer components.

\subsubsection{The effect of Rayleigh number:}

Since the aim is to study the turbulent flow, a rage of Rayleigh numbers between $10^{9}$ and $10^{10}$ were investigated. Constant amount for other dimensionless numbers in this state are as follows:

$$
R e_{B}=5, \operatorname{Pr}=0.72, \text { Stef }=200, H / L=4, d / L=0 / 008
$$

In figure (4), the flow line is shown with changes in Rayleigh. In lower Rayleigh numbers, gradient of the function is small, indicating a low speed. Gradually, with the increase in Rayleigh number, the effect of Rayleigh on Reynolds becomes dominant, the gradient flow function near the wall as well as velocity increase, resulting a reduction in boundary layer thickness. Also in figure (5), the lines with the same temperature are shown. In low Rayleigh numbers, the heat boundary layer thickness is over both large walls. There is a fluid layer with same temperature as the wall near the blowing wall, but gradually the temperature gradient starts and continues to reach the free flow temperature. as the Rayleigh number increases, the heat boundary layer thickness decreases so that, in $10^{12}$ Rayleigh number, except for a thin layer near the wall which flows the extreme temperature gradient, the temperature is equal to the temperature of the input free flow in all the other channel. 


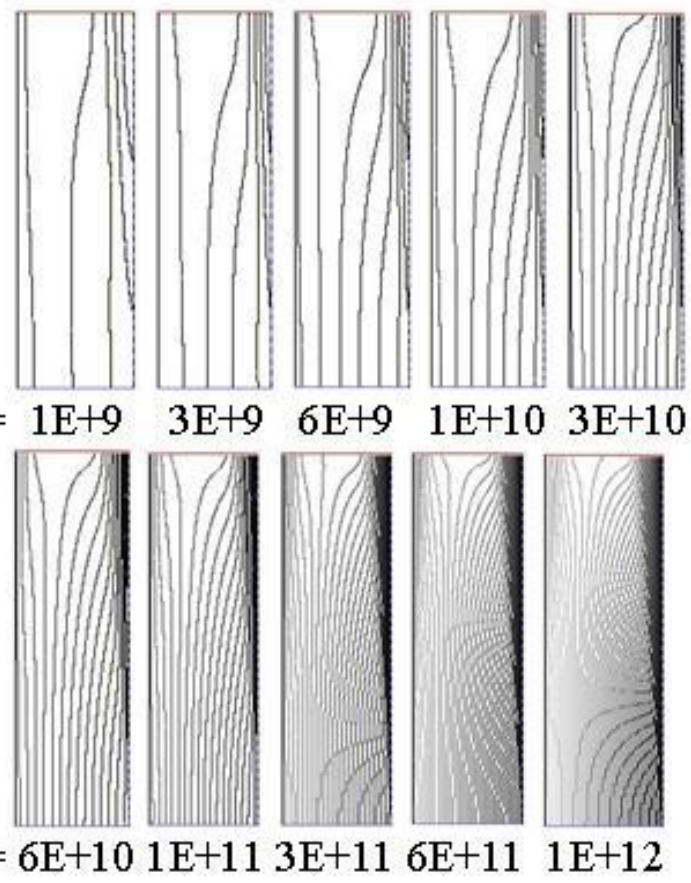

Figure 4. The effect of Rayleigh on flow lines in the channel

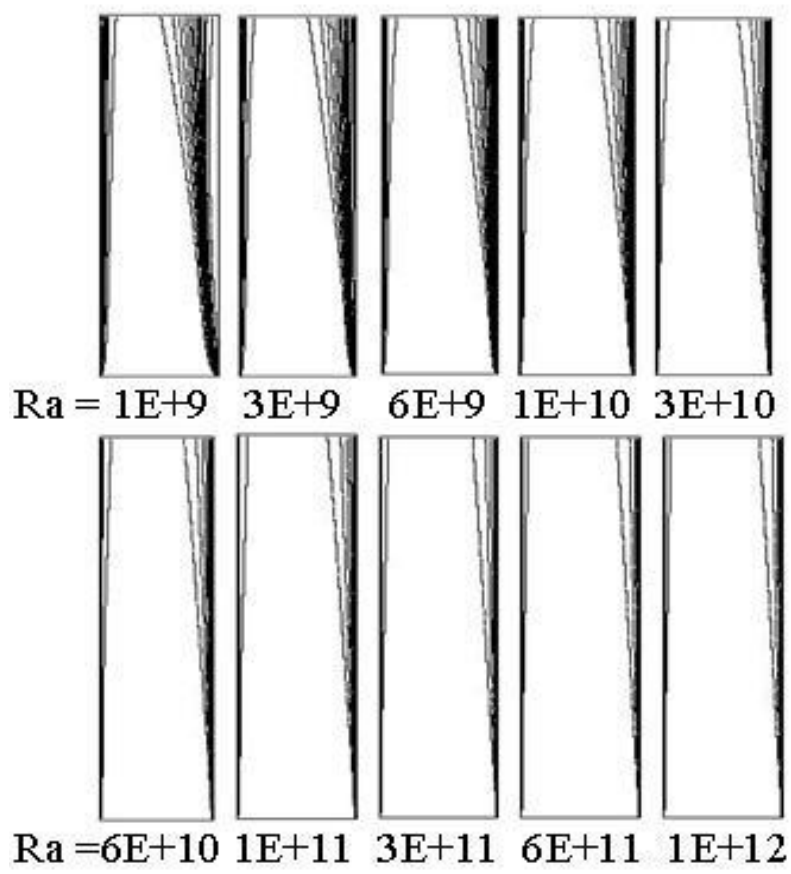

Figure 5. The effect of Rayleigh number on the constant temperature lines in the channel

Figure (6) shows that as the Rayleigh increases, the role of blowing and radiation in heat transfer gradually decreases to $15 \%$ and $5 \%$, while a $20 \%$ increase is observed for convection heat transfer. In figure (7), Nusslet number for free convection and the ratio of radiation to Rayleigh number are drawn. In low Rayleigh numbers, there is high dependence of radiation Nusslet on the Rayleigh number, but in Rayleigh numbers more than $10^{11}$, the amount of radiation Nusslet almost remains stable. This changing trend is due to the fact that in low Rayleigh numbers, the increase in the Rayleigh causes an increase in the flow velocity in the 
channel and cooling of the isolated wall, where the isolated wall temperature nearly reaches the input flow temperature. Following that, the change in Rayleigh number does not have a significant effect on the isolate wall temperature and radiation Nusslet. Also, for free convection Nusslet, the diagram shows of 400 units for the changes in Rayleigh from $10^{9}$ to $10^{12}$, and in high Rayleigh numbers, convection Nusslet increases sharply.

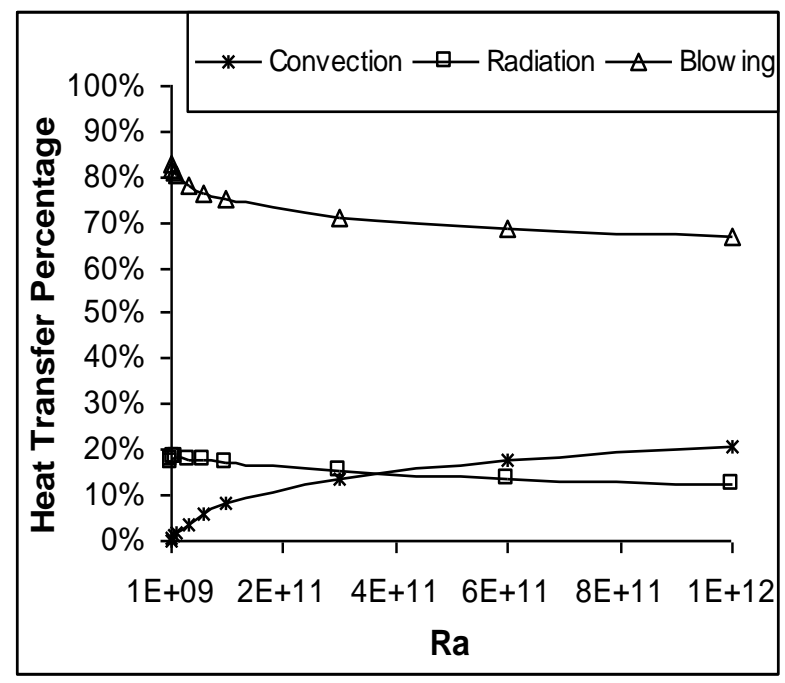

Figure 6. The effect of Rayleigh number on the percentages of heat transfer

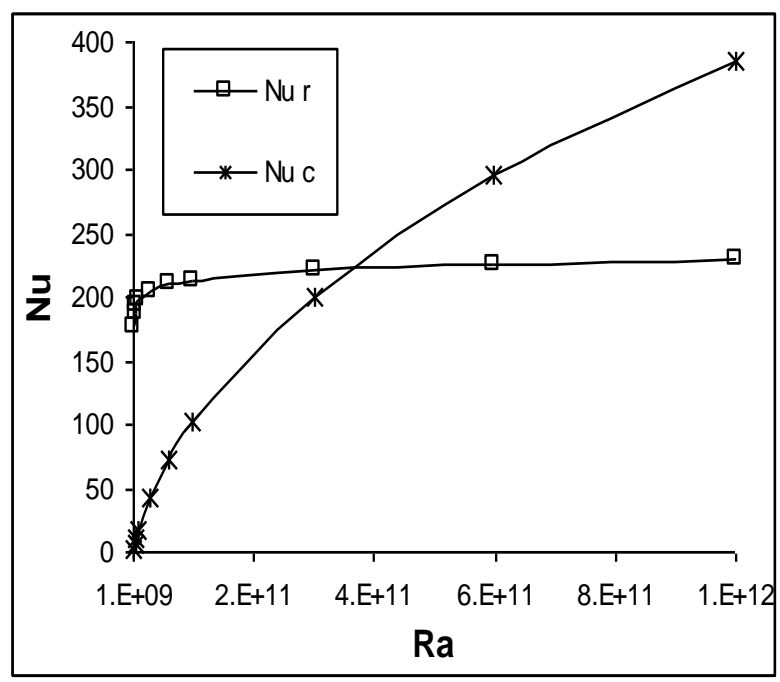

Figure 7. The effect of Rayleigh number on the convection Nusslet and radiation Nusslet

Figure (8), shows the changes in blowing Nusslet and total Nusslet. The increase in flow turbulence and velocity increases the heat penetration and causes the blowing Nusslet to increase by 400 units. There is also an increasing trend for the total Nusslet which shows an overall change in heat transfer components. 


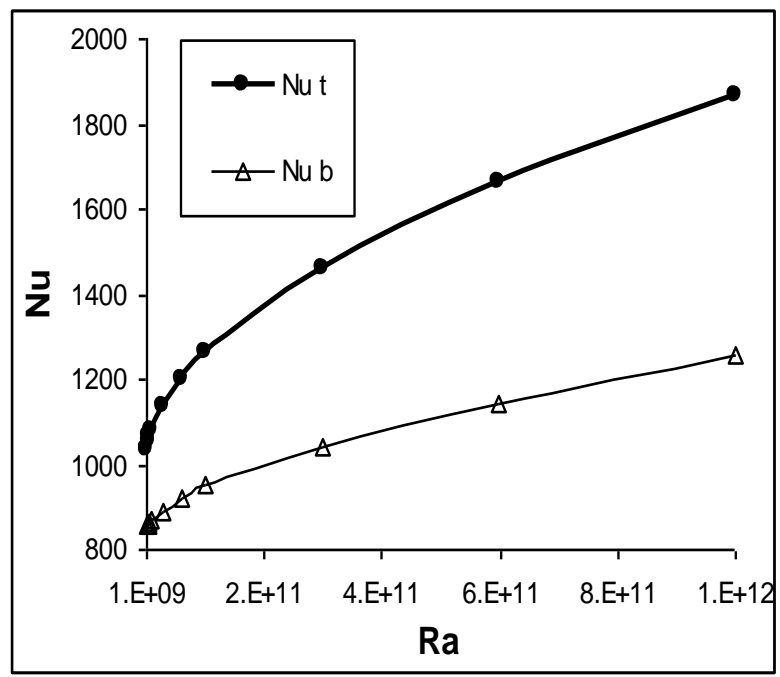

Figure 8. The effect of Rayleigh number on the blowing and total Nusslet

\subsubsection{The effect of blowing Reynolds number:}

To study the effect of Reynolds number, arrange of Reynolds between 0 and 15 were analysed. The fixed values for the other dimensionless numbers in this mode are selected as follows:

$$
R a_{H}=10^{10}, \operatorname{Pr}=0.72, \text { Stef }=200, H / L=4, d / L=0 / 008
$$

In figure (9), it is observed that as the blowing Reynolds increases, the boundary layer thickness and flow gradient function on the blowing wall gradually decreases. The velocity in the channel as well as the cold air intake also increases. The temperature boundary layer in the blowing wall in figure (10) shows an increase in the temperature gradient and thickness as the Reynolds increases which has a negative influence on the heat transfer convection. High insulating wall boundary layer is not affected by increasing Reynolds.

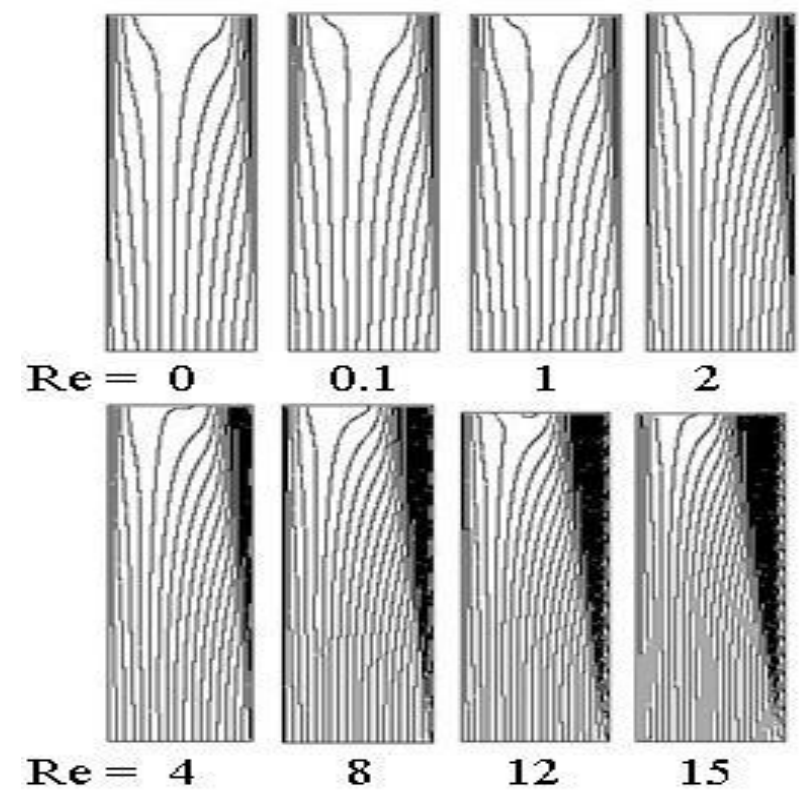

Figure 9. The effect of Reynolds number on flow line in the channel 


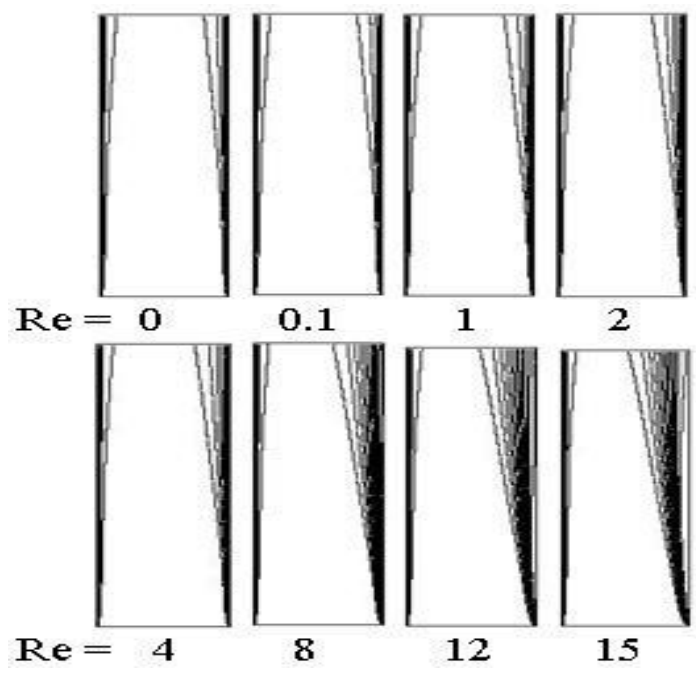

Figure 10. The effect of Reynolds number on the isotherms channel

In figure (11), it is clear that in non-blowing mode, the blowing is 55\% through radiation heat transfer and the rest is done by convection. However, as the Reynolds increases, blowing play the most important role in heat transfer. Figure (12) shows that the effect of blowing Reynolds on radiation Nusslet is insignificant, while the free convection Nusslet dramatically decreases as the blowing Reynolds increases. The heat gas blowing causes a heated fluid layer to between the wall and the cold fluid which blocks the free heat convection. This is because the convection Nusslet decreases up to 80 units as the blowing starts even with a low Reynolds $(\operatorname{Re}=0.1)$, and in Reynolds number 15, Nusslet convection in insignificant.

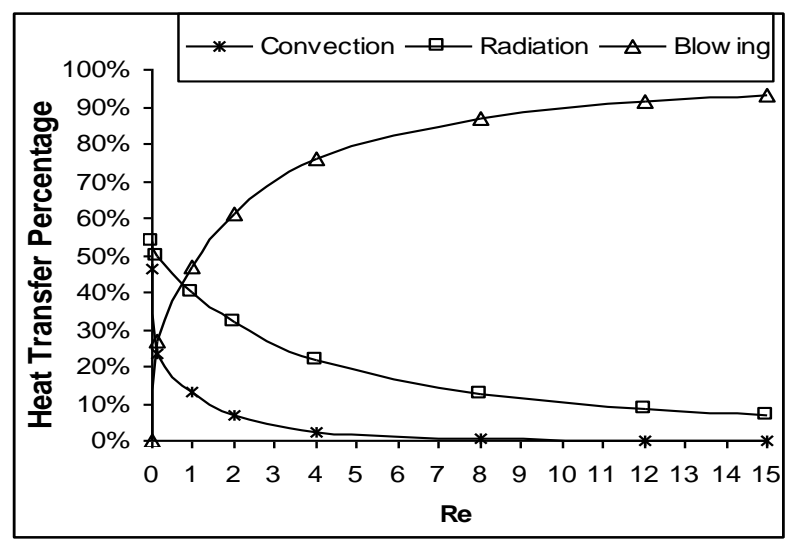

Figure 11. The effect of Reynolds number on the percentage of heat transfer components 


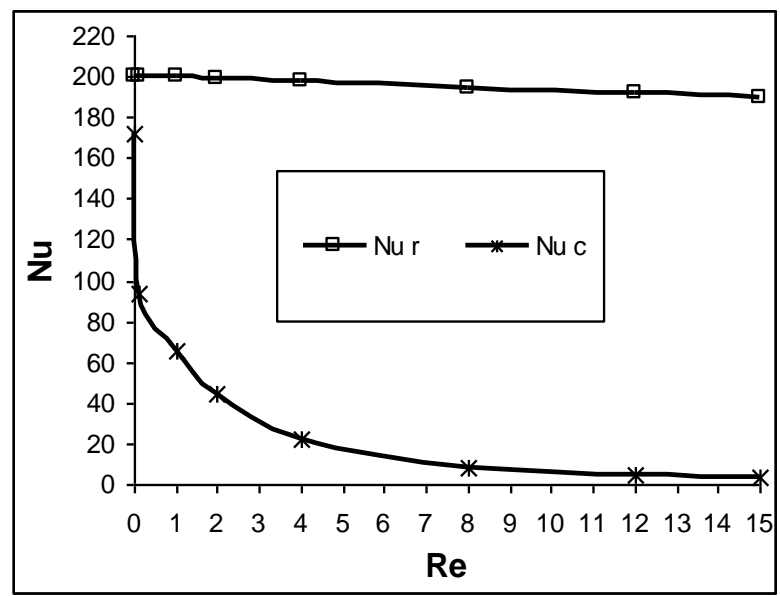

Figure 12. The effect of Reynolds number on convection Nusslet and radiation Nusslet

Figure 13 shows that there is a linear relation between the blowing Nusslet number and Reynolds. Also, the total Nusslet is the most effect by the blowing Reynolds, increases linearly with a close difference, which is cause by the radiation Reynolds.

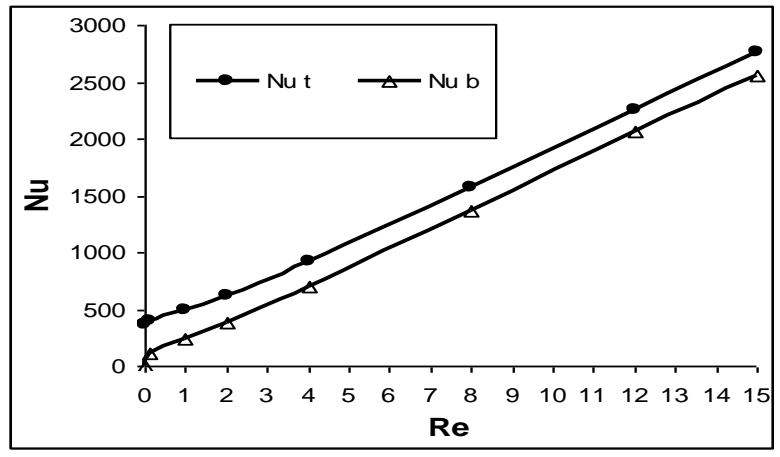

Figure 13. The effect of Stefan number on the blowing Nusslet and total Nusslet

\subsubsection{The effect of Stefan number:}

In order to study the effect of radiation parameters, a range of Stefan numbers from 0 to 250 were analysed. Fixed values for other dimensionless numbers in this mode were selected as follows:

$$
R a_{H}=10^{10}, R e_{B}=5, P r=0.72, H / L=4, d / L=0 / 008
$$

As shown in figure (14), in non-radiation mode, the existence of return flow causes a vortex in the outlet which is considered to be a block for the flow. With the start of radiation and fluid flow on the isolated wall, the vortex disappears, and gradually increases as the Stefan number of the flow gradient function and the velocity on the isolated wall go up. 


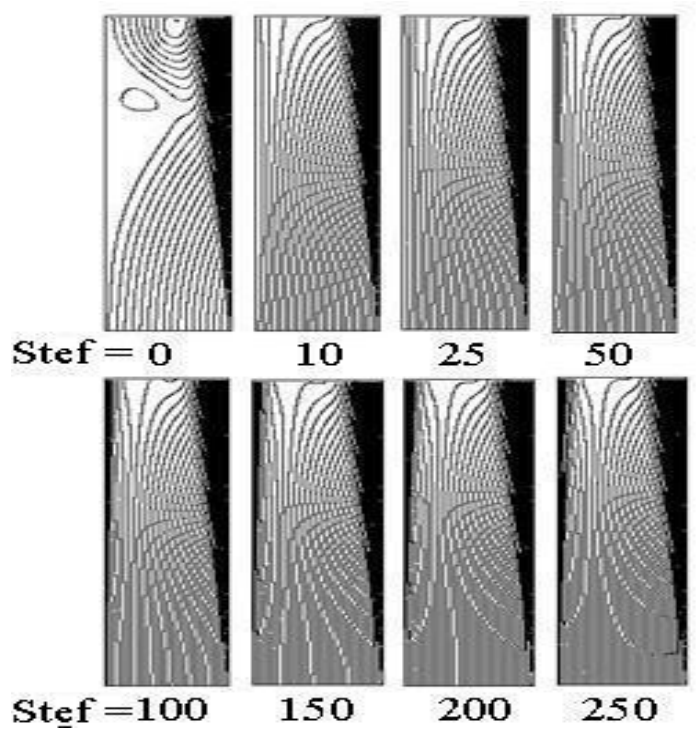

Figure (14). The effect of Stefan number on the flow lines in the channel

In figure (15), it is observed that the increase in the Stefan number does not have a significant influence on the heat boundary levels of blowing wall, but the heat boundary layer thickness as well as the isotherm line gradients on the isolated wall have a rising effect.

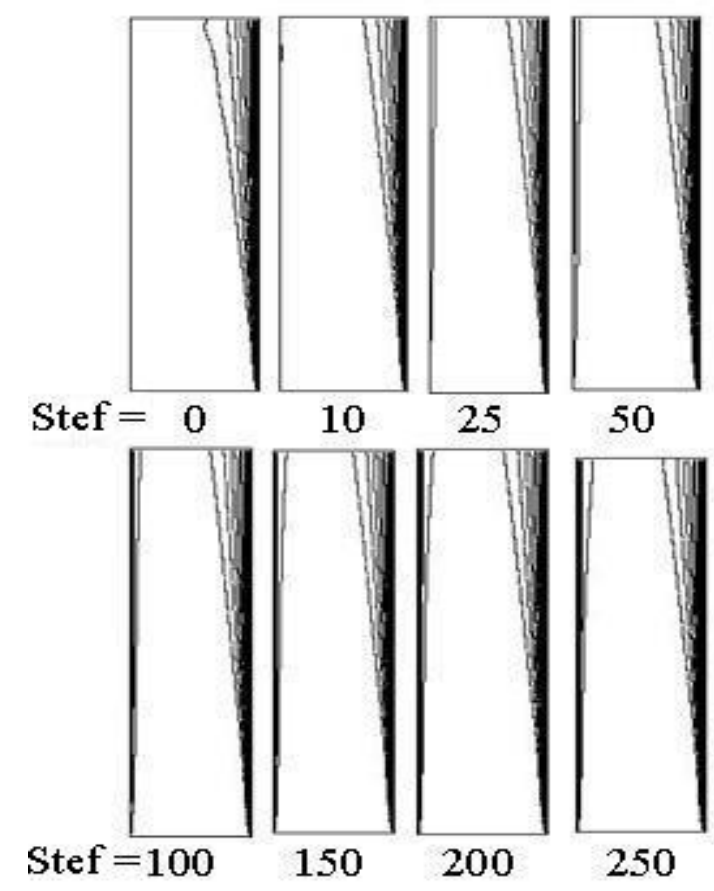

Figure 15. The effect of Stefan number on the isotherm lines in the channel

In figure (16), it is illustrated that as the Stefan number increases, the impact of radiation in transfer increase by $20 \%$ and the impact of blowing decreases $20 \%$, while the impact of convection is insignificant and remains constant. 


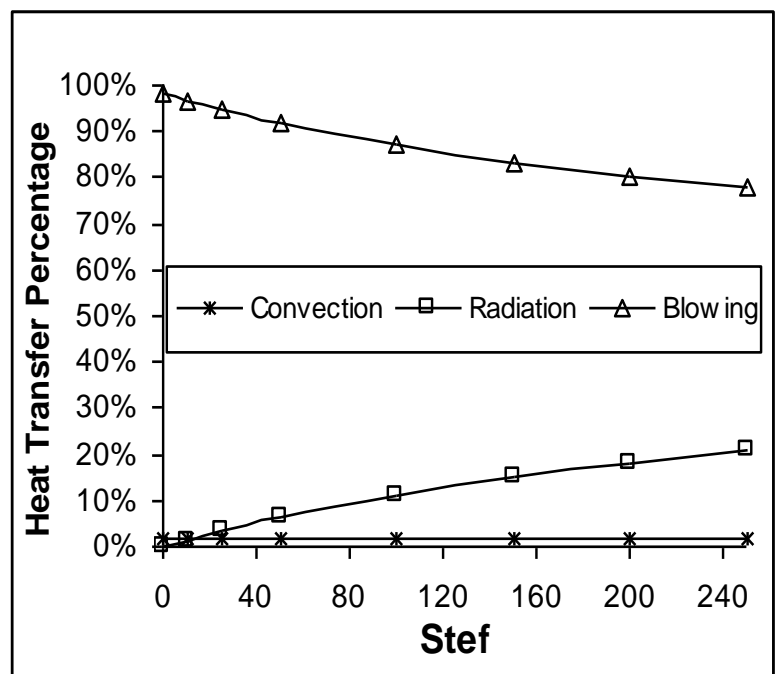

Figure 16. The effect of Stefan number on the percentage of heat transfer components.

It can be seen in figure 17 that, as the Stefan number increases, convection Nusslet remains constant, whereas the radiation Nusslet increases downward with a slight concave.

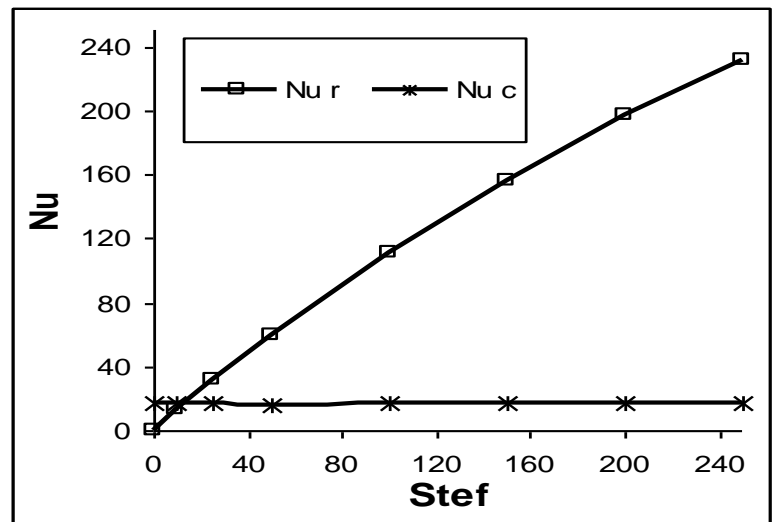

Figure 17. The effect of Stefan number on the convection Nusslet and radiation Nusslet

In figure (18), it can be observed that the amount of Nusslet is independent of radiation parameter. Also the total Nusslet is affected by the radiation Nusslet and has an increasing trend. 


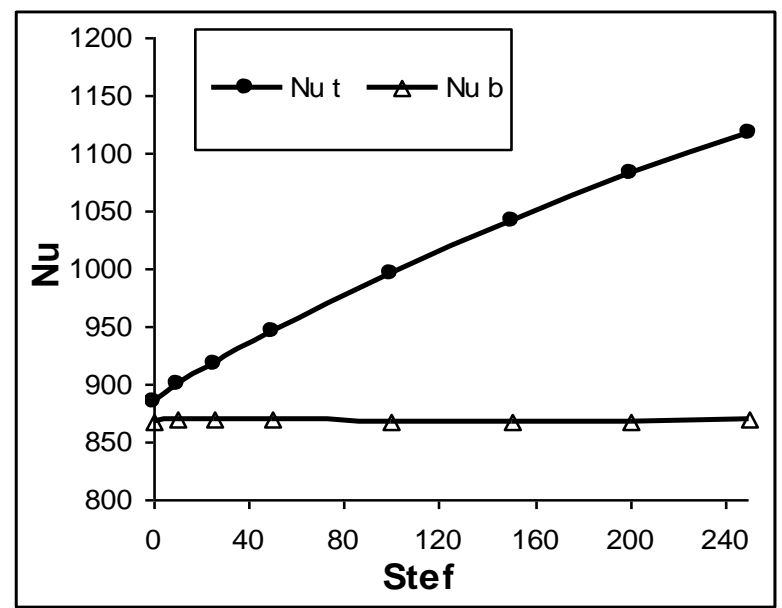

Figure 18. The effect of Stefan number on blowing Nusslet and total Nusslet

\subsubsection{The effect of Prandtl number:}

In order to study the effect of Prandtl number, range of Prandtl number from 0.1 to 1 were analysed. Fixed values for other dimensionless numbers in this mode were selected as follows:

$$
R a_{H}=10^{10}, R e_{B}=5, \text { Stef }=200, H / L=4, d / L=0 / 008
$$

Figure (19) shows the effect of Prandtl number on the transfer lines. in low Prandtl numbers, the boundary layer thickness is high on both small wall and flow gradient function as well as the velocity near the wall are high, but as the Prandtl number goes up, viscosity dominates the heat penetration and as a result the flow velocity and the flow gradient function decrease.

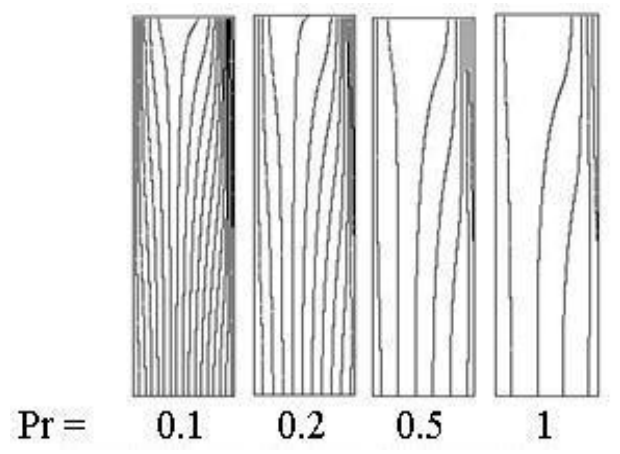

Figure 19. The effect of Prandtl number on the isotherm lines in the channel.

As the flow velocity decreases in the channel, the effect of blowing becomes more apparent and the boundary layer thickness of the blowing wall extends. This causes to create a thick isotherm layer of heated blown fluid near the heated wall. This trend is visible in isotherm lines which are shown in figure (20). 


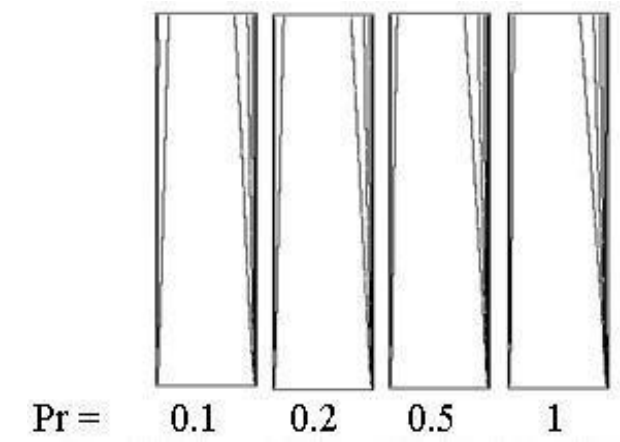

Figure 20. The effect of Prandtl number on isotherm lines in the channel

as shown in figure (21), in low Prandtl numbers, the impacts of radiation and free convection are insignificant, but as the Prandtl number increases, their impacts reduces, so that for Prandtl number 1 , more than $80 \%$ of heat transfer is done through blowing.

Figure 21. The effect of Prandtl on the total percentage of the heat transfer components

From figure (22), it can be understood that the convection Nusslet highly depends on the Prandtl number. The extension of the boundary layer thickness which is caused by the increase in the Prandtl number causes the heat transfer convection to be more resistant which decreases the free convection. However, the increase in Prandtl has no effect on the radiation Nusslet.
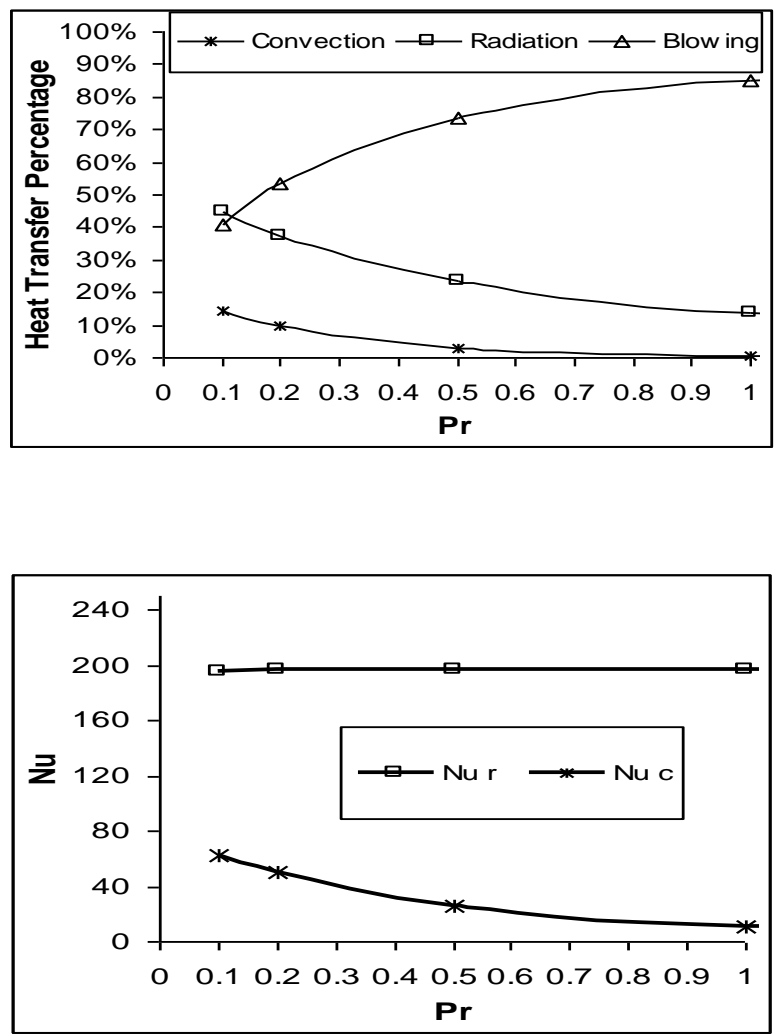

Figure 22. The effect of Prandtl number on the convection Nusslet and radiation Nusslet

Figure (23) shows that in high Prandtl numbers, heat transfer caused by blowing mass transfer is so high that the total Nusslet is only affected by blowing Nusslet and increase sharply in a linear way. 


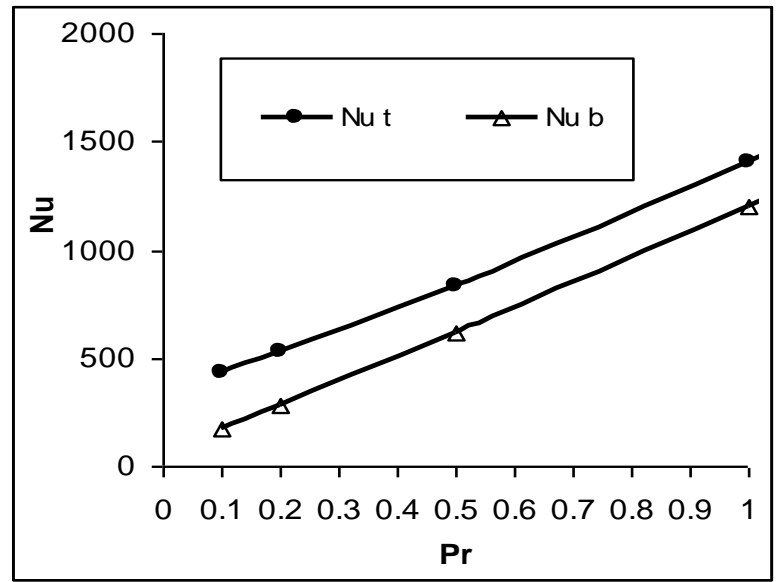

Figure 23. The effect of Prandtl number on blowing Nusslet and total Nusslet

\section{Conclusions}

By analysing the results, it can be perceived that, the blowing gas from the wall, without being effective on the amount of radiation, can play a crucial role in total heat transfer, through mass transfer. The heated gas blowing in the channel creates a Buffer layer and decreases heat transfer convection from the wall. Although radiation heat transfer works independent of blowing and convection, the lack of radiation causes a return flow. Also heat transfer convection, flow velocity in the channel and boundary layer thickness highly depend on Prandtl number.

\section{References}

[1] Miyamoto, M., Katoh, Y., Kurima, J. and Saki, H., "Turbulent free convection heat transfer from vertical parallel plate", Heat Transfer, eds C.L.Tien, V.P.Carry and J.K.Ferrel, Vol. 4, Hemisphere Washington DC, pp. 1593-1598, 1986.

[2] Fedorov, A. G., and Viskanta, R., "Turbulent natural convection heat transfer in an asymmetrically heated vertical parallel plate channel", Int. J. Heat Mass Transfer, Vol. 40, pp. 3849-3860, 1997.

[3] Eichhorn, R., "The effect of mass transfer on free convection", J. of Heat Transfer, Vol. 82, pp. 260-263, 1960.

[4] Merkin, J. H., "Free Convection with Blowing and Suction", Int. J. Heat Mass Transfer, Vol. 15, pp. 989-999, 1972.

[5] Vedhanayagam, M., Altenkirch R. A., Eichhorn, R., "A Transformation of the Boundary Layer Equations for Free Convection Past a Vertical Flat Plate with Arbitrary Blowing and Wall Temperature Variations", Int. J. Heat Mass Transfer, Vol. 23, pp. 1286-1288, 1980.

[6] Brouwers, H. J. H., "The Film Model Applied to Free Convection Over a Vertical Plate with Blowing or Suction", Int. J. Heat Mass Transfer, Vol. 35, No. 7, pp. 1841-1844, 1992.

[7] Grosan, T., and Pop, I., "Thermal radiation effect on fully developed mixed convection flow in a vertical channel", Technische Mechanik, Band 27, Heft 1, pp. 37-47, 2007.

[8] CHENG, X., and MULLER, U., "Turbulent natural convection coupled with thermal radiation in large vertical channels with asymmetric heating", Int. J. Heat Mass Transfer, Vol. 41, No. 12, pp. 1681-1692, 1998. 
[9] Abd El-Aziz, M., "Thermal-diffusion and diffusion-thermo effects on combined heat and mass transfer by hydromagnetic three-dimensional free convection over a permeable stretching surface with radiation", Physics Letters A, Vol. 372, pp. 269-276, 2008.

\section{Authors}

Samak. Hosseinzadeh was born in August 22nd 1985 in Sari, Mazandaran. He is a $\mathrm{PhD}$ student in Mechanical Engineering (Energy Conversion) at Islamic Azad University, West Tehran Branch, Tehran, Iran. He also received his Ms. Degree in mechanical engineering (Energy Conversion) from South Tehran Branch in 2010.He did his military service in Manufacturing, Mining and Trade organization as an industry expert from 2010 to 2012 . He is currently a university lecturer in Islamic Azad Universities in Mazandaran, Iran. The teaching courses included Thermodynamics, Heat Transfer, Mechanical technology, Automotive and Machinery. He also was a Technical Office Manager in Nogostaran Construction Installation Company in Tehran from 2007 till now. He is a member of Iran Construction Engineering organization.

Ali yari was born in Septembr 21nd 1983 in Qaemshahr, Mazandaran. He received his Ms. Degree in mechanical engineering (Energy Conversion) from Shiraz University, Shiraz, Iran. He also received his BSc degree in thermal fluids from in thermal fluids from Babol, Noshirvani University of Technology, Babol, Mazandaran.He did his military service in Education as a Soldier teacher from 2010 to 2012. He is currently a university lecturer in Universities in Mazandaran, Iran. The teaching courses included Thermodynamics and Heat Transfer.

Amin. Bahrami was born in September 22nd 1986 in Gorgan, Golestan. He received his MS. Degree in mechanical engineering, Energy conversion From Iran University of Science and Technology in 2010. He also received his BSc degree in thermal fluid from Azad Islamic University Sari Branch, Mazandaran. $\mathrm{He}$ is currently university lecturer in Islamic Azad Universities in Golestan, Iran. Also, he is an employer in Organization of School Renovation. He is a member of young researchers club in Iran and Iran Engineering Organization Structure too. Hi was chosen as the top student at the Iran University of Science and Technology in 2010 and as an undergraduate student, he was elected second.

Morteza Radmanesh was born in August 29nd 1995 in Tehran,Tehran. He is a student in Mechanical (mechanical installation) at Institute of Higher Education Roozbahanal in Sari, Mazandaran. He is also the designer of mechanical systems in Company of Industry facility in Sari,Mazandaran, Iran.
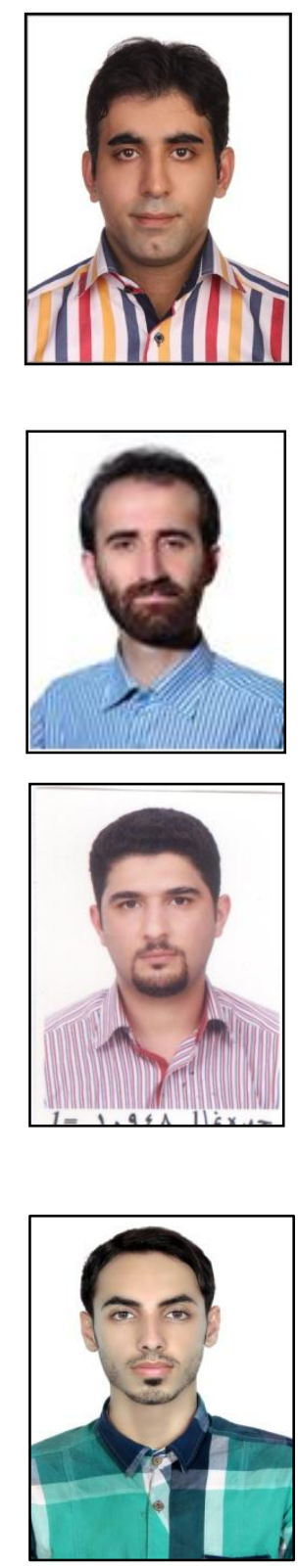